\title{
How efficient is an integrative approach in archaeological geophysics? Comparative case studies from Neolithic settlements in Thessaly (Central Greece)
}

\author{
F.-X. Simon*, T. Kalayci, J.C. Donati, C. Cuenca Garcia, M. Manataki and
}

A. Sarris

Received December 2014, revision accepted September 2015

\begin{abstract}
The geophysical prospection of Neolithic tells imposes specific challenges due to the preservation and nature of the architectural context and the multiple, usually disturbed, soil strata. Contrary to the usual application of a single method, this paper deals with the advantages of using an integrated geophysical approach through the employment of various methodologies to map the Neolithic cultural and environmental landscape of Thessalian tells (magoules) in Central Greece. The success and failure of each method in resolving the various features of the magoules are discussed in detail, and as a whole, they demonstrate the benefits of a manifold geophysical prospection of the sites.
\end{abstract}

\section{INTRODUCTION}

Today, it is common in Geophysics to use more than one technique for the characterization of an archaeological site (Vafidis et al. 2005; Drahor 2006; Cardarelli and Di Filippo 2009; Keay et al. 2009; Sarris 2013). Surveys that rely on a single technique may not identify features of archaeological interest because of the complex contrast dynamics between the distinct geological and environmental conditions at the site and man-made conditions. Therefore, the efficiency of using several techniques, when possible, such as ground-penetrating radar (GPR), magnetics, or resistivity, is a more reliable approach to ensure the success of an archaeological survey.

In this paper, we assess an integrative approach for the documentation of Neolithic tell settlements in the eastern region of Thessaly (Magnesia) of Central Greece. We investigate to what degree integrated methodologies are successful in the detection of prehistoric settlements and whether multiple sensors are able to map (relatively) modest features of archaeological interest common at Neolithic sites, such as mudbrick architecture and enclosure ditches. Knowing in advance that Neolithic settlements present challenges for geophysical prospection, we present the results of two integrated geophysical surveys carried out on multilayered sites in Thessaly to assess how much the characteristics of a given site influences the success of an integrative approach.

\section{THE PROJECT}

Innovative Geophysical Approaches for the Study of Early Agricultural Villages of Neolithic Thessaly (IGEAN) deals with a systematic and extensive geophysical survey at more

*fxsimus@hotmail.com than 15 Neolithic tell sites, which are locally referred to as magoules. The archaeological objective is the study of early prehistoric farming settlements, their development, and intrasite connectivity. The systematic mapping of the sites and their local environmental contexts generate different models of construction and space usage in the eastern region of Thessaly during the Neolithic period. Until now, only a limited number of magoules have been extensively excavated and surveyed, and many are rapidly being damaged by intensive farming activity. The IGEAN project provides valuable information for their macro- and micro-scale fabric. The implementation of a multi-site approach also provides information on the potential variation in Neolithic habitation patterns in terms of the natural environment, identifying both common and divergent elements. IGEAN follows in the footsteps of a number of significant projects in Thessaly. Previous geophysical campaigns have been carried out at Zerelia (Papadopoulos, Sarris, and Salvi 2011) and Dimini (Sarris et al. 2001), two major Neolithic sites in Thessaly (Demoule and Perlès 1993), and most recently at Koutroulou magoula by the British School at Athens (Hamilakis and Kyparissi-Apostolika 2012) and the Aristotle University of Thessaloniki (Tsokas et al. 2009). The results demonstrate the potential for geophysical methods in the characterization of Neolithic settlements. However, it is important to point out that the focus of these previous studies has been on singular contexts and not the regional approach of IGEAN. In addition to geophysical prospection, a study of the landscape and of the geology of the Thessalian plain has been recently completed through remote sensing tools using different datasets (Alexakis et al. 2009; Agapiou et al. 2012). This study revealed not only a high density of settlements in the 
plain but also, by a mathematical spatial approach, their connectivity.

IGEAN implements a specific strategy for the fast and highresolution assessment of the subsurface by using the latest generation of instruments, including multi-sensors supported with a sub-centimeter positioning system (GPS-RTK). Magnetic and electromagnetic techniques are employed as a fast and robust system, along with ground-penetrating radar, magnetic susceptibility, soil resistance, low-altitude aerial photography (using unmanned aerial vehicles), and chemical analysis by coring. The soil sample analysis from the topsoil, which is a part of the project, will be presented in a separate paper. Between 2013 and 2014, the project surveyed 16 magoules in three campaigns with a total duration of five weeks (Fig. 1). We discuss here the complementary nature of the geophysical datasets in revealing the prehistoric landscapes,

\section{KNOWLEDGE ON TELLS AND GEOPHYSICAL RESPONSE}

Up to the present, only three Neolithic sites have been extensively excavated in Thessaly. Diminia, Sesklo and Palioskala (Toufexis 2006; Halstead 1992; Wijnen 1981) are considered classic examples of the Neolithic culture in eastern Thessaly. The sites not only give a picture of the complexity of these settlements but also some indication about the template of houses and the patterns of internal spatial organization. Nevertheless, the sites have only been partially exposed through archaeological excavations and therefore provide only a partial illustration of the extended settlement (in terms of the local scale).

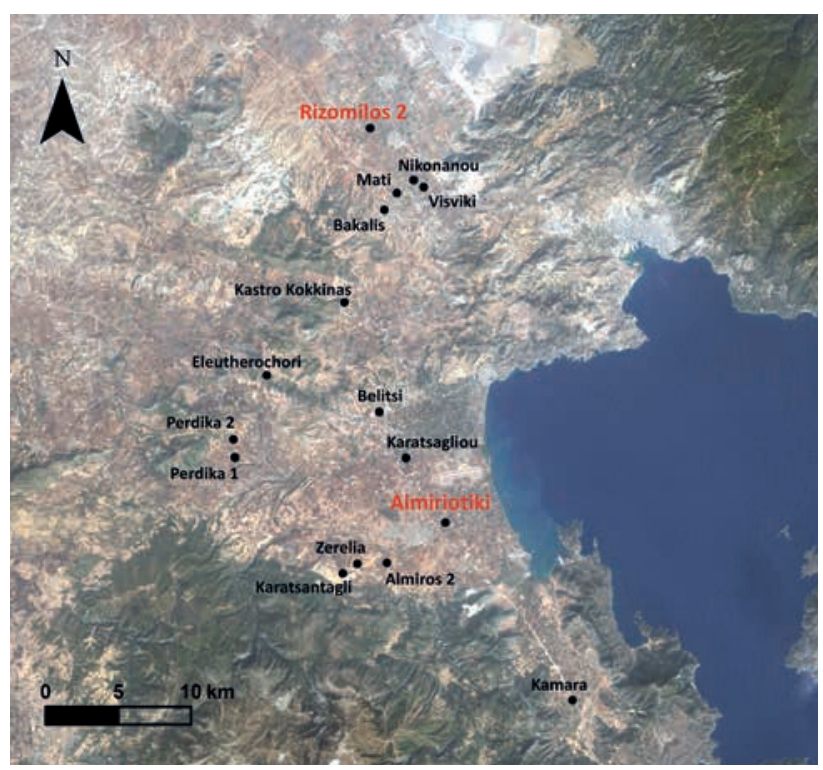

FIGURE 1

Location of the Neolithic settlements surveyed for the IGEAN Project in the region of Thessaly (Greece). Those in red are the two case-studies for the present study.
Magoules constitute anthropogenic formations, which result from the accumulation of cultural sediments over hundreds and even thousands of years. A constant or episodic occupation of the settlement with some phases of destruction or abandonment (Stevanović 1997) creates new layers of material as a basis for newer buildings (Wijnen 1981). This situation presents many challenges for the geophysical characterization of an individual site. The stratification of material is difficult to differentiate due to the poor contrast of geophysical properties between occupation layers. In addition to the habitation mounds, settlement activity could also expand to the periphery and even into the surrounding plains (Bailey et al. 2002; Bailey et al. 1998). This aspect of early farming villages in eastern Thessaly is poorly understood, and it is rarely documented by previous archaeological fieldwork. The morphological definition of the site requires a multi-depth approach with a geophysical survey. For IGEAN, we choose to follow a specific methodology, i.e., to cover at first a large area, which means the main part of the hill and the peripheral areas, then to confirm the spatial extension of the Neolithic site, and finally to accurately map specific targets using a wide range of prospection tools.

\section{METHODOLOGY AND INSTRUMENTATION}

Regarding previous studies on prehistoric tells and stratified sites, even if the accurate characterization of archaeological features cannot be obtained, geophysical tools still provide valuable information on the main orientation of the site and its major buildings. In particular, Ground-penetrating radar (GPR) has been successfully used to map major targets as well as to record the depth of archaeological features. Previous results provide good data, especially for multi-layered sites representing the last occupation of the settlement (Casana, Herrmann, and Fogel 2008; Novo, Vincent, and Levy 2012). On the other hand, the low contrast of electrical properties within this melting pot of structures and archaeological layers limits the effectiveness of electrical tomography, although it does provide certain advantages for understanding the geomorphological context (Papadopoulos et al. 2014) and for identifying the global orientation and general stratigraphy of some sites (Berge and Drahor 2011). Magnetics are often successful in showing the full extent of a settlement. However, high magnetic anomalies on the top of a site often mask the anomalies of a lower magnetization or deeper position (Schmidt and Fazeli 2007; Yerkes et al. 2007).

Mindful of these limitations, our global methodological approach first adopts a large magnetic survey on and around the Neolithic magoules. Simultaneously, we use a multi-frequency electromagnetic (EM) interference to characterize both electrical conductivity and magnetic susceptibility at a specific depth (Tabbagh 1986). Smaller targeted areas on the top and the sides of the magoules are selected for GPR. Depending on the initial results of EM, we may also decide to take multi-depth measurements with a CMD-Mini explorer. 
The magnetic survey was carried out with a parallel configuration of fluxgate gradiometers from Sensys Gmbh with a vertical spacing of sensors of $650 \mathrm{~mm}$. Eight sensors are simultaneously used to cover a broad band of land. Each sensor is fixed at $0.5 \mathrm{~m}$ and attached to a frame with four wheels maintaining relative stability of the cart. A measurement is then recorded every $5 \mathrm{~cm}$ to $10 \mathrm{~cm}$ along each profile $50 \mathrm{~cm}$ apart. The remote antenna of the differential GPS (dGPS) is also fixed on the unit. The eight sensors and the GPS are connected to a multi-channel box, as suggested by Sensys Gmbh. All data are then collected by a ToughPad or ToughBook. The whole setup extracts data with real-time software (MomX from Sensys) and records the position of the unit during data acquisition and the quality of the dGPS signal. The use of a ToughPad on the frame reduces the manpower required to map magnetic data to two surveyors, who are able to cover 2-3 ha per day on moderately rough terrain. In the case of a continuous survey with this kind of sensor, profile and directional effect (induced by the ploughlines), strongly affect the data. To process the data, we use different linear filtering (using a fast Fourier transform and removing the directional signal that is considered noise, by manual selection or angular discrimination) and other classic processing techniques, such as despiking and median filtering. The limitations of magnetics still remain the approximate depth of investigation and the deformation between the shape of the archaeological target and the shape of the anomaly, which is affected by depth and magnetization (Desvignes, Tabbagh, and Benech 1999).

For EM measurements, we employed two different sensors in the field: (i) GEM-2 from Geophex and (ii) CMD-Mini explorer from GF Instrument, with a GPS unit in order to maximize the daily coverage. These instruments are particularly adapted for this kind of integrative approach because they offer a multi-depth and multi-parameter dataset. The GEM-2 is a multi-frequency EM instrument with two coils spaced by $1.66 \mathrm{~m}$, collecting data at five different frequencies. The CMD-Mini explorer is a multispacing coplanar coil with three spacing, i.e., $0.32 \mathrm{~m}, 0.71 \mathrm{~m}$, and $1.18 \mathrm{~m}$, meaning that three different depths are simultaneously studied in the field. The in-line sample density of the GEM-2 was $1 \mathrm{~m}$ and $0.5 \mathrm{~m}$ for the CMD. Both sensors were used with 1-m profile spacing. At times, GEM-2 was used with a 5-m profile spacing to map geomorphological features. GEM-2 was used to measure simultaneously soil conductivity and susceptibility at one deep depth of investigation. The same properties were also simultaneously characterized by the CMD but at three shallow depths. We used the same processing tools for the magnetic data to remove the striping effect, which is induced by the slight modification of the sensor's geometry. EM instrumentation requires proper calibration for the production of meaningful results (Thiesson et al. 2014). Although this calibration is easy for the electrical conductivity, the stability of the instrument usually does not provide a very good characterization of the absolute magnetic susceptibility. This potential error could affect the mathematical process of the EM signal, and as a result, the joint interpretation of the magnetic and EM data could be distorted (Desvignes et al. 1999; Tabbagh 1984; Benech, Tabbagh, and Desvignes 2002). We bypass this problem by using a systematic calibration procedure (Thiesson et al. 2014). The different magnetic properties from the EM can be then compared with the magnetic data (Pétronille et al. 2010; Simon, Koziol, and Thiesson 2012).

A Noggin Plus-Smart Cart system by Sensors \& Software equipped with a $250-\mathrm{MHz}$ antenna was used for the GPR survey. Grids were designated to delimit discrete areas of interest, and the data were collected every $2.5 \mathrm{~cm}$ along $50-\mathrm{cm}$ parallel traverses. The GPR datasets were processed using EKKO View Deluxe, GFP Edit4, EKKO Mapper4, and EKKO Project 2 by Sensors and Software. The process that was applied removed noise from the data and enhanced the signal's information that leads to a better representation of the subsoil. Processing is divided in two stages: the first deals with the application of correctional filters separately on every survey line, whereas the second stage deals with the extraction of slices in accordance to depth. During the first stage, the following filters and corrections were used: traces decomposition (namely the representation of the traces in their harmonic components), time zero correction, dewow filter, spreading and exponential correction gain, background subtraction, and filtering frequency domain (high pass, low pass, and band filters). The latter decomposes the GPR signals to a finite number of intrinsic mode functions. Even if this technique does not allow a direct comparison with other data, regarding the nature of the physical properties, in most cases, it is sensitive to the same features. The effectiveness of the methods can also be compared with the conductivity of the soil, as an explanation of the failure observed for some areas.

The manifold dataset gives valuable information about subsurface features. To merge this multi-parameter, multi-depth information that we used, when possible, a process of joint interpretation of the EM and magnetic data (Benech et al. 2002) that provides an analysis of the different magnetization (induced and remanent) for different depths. In other cases, our integrative approach benefited from the information derived by the GPR survey about the depth and the thickness of some structures.

\section{CASE STUdIES}

Two sites are presented here that characterize the advantages and limitation of implementing an integrated geophysical approach to the study of Neolithic magoules. The first example, Rizomilos 2, is $2 \mathrm{~km}$ northwest of the farming village of Rizomilos in the area of the southern Larissa plain. The second example, Magoula Almiriotiki, is located $2 \mathrm{~km}$ from the village of Almiros within the coastal plain of Eastern Thessaly. Both are located in the eastern region of Thessaly. A field survey carried out by the Archaeological Ephorate of Magnesia shows that Almiriotiki had multiple occupation phases that span the Early Neolithic period up to the Late Bronze Age (Vouzaxakis 2008). Likewise, the major occupation phases of Rizomilos 2 fall within the Neolithic period, although 
in this instance the extent of later activity is unclear from the lack of archaeological exploration. Prior to geophysical survey, both sites were examined by high-resolution $(0.5 \mathrm{~m}-0.6 \mathrm{~m})$ multispectral satellite imagery (GeoEye-1, Quickbird, and WorldView-2) and historical aerial photographs acquired from the Hellenic Military Geographical Service to gain a sense of the extent of each settlement and the local environment.

\section{Rizomilos 2}

Vegetation stress in the satellite imagery related to subsurface features (presumably from the magoula) gives a clear picture of the settlement's extent, showing a large anisotropic extension of the site around the tell. This initial remote sensing analysis proved useful for the estimation of the target area, although it did not show any clear archaeological features, limiting the use of spaceborn remote sensing studies to the global detection of the tell. Nevertheless, some satellite views identify geomorphological features, such as palaeaochannels and terraces. This undated information can be useful in providing prior information on the geomorphological and hydrological systems.

Magnetic results show most clearly the structure of this site (Fig. 2). It is constructed in two parts as two concentrated settlements: the bigger one, on the western side, and a smaller peripheral one on the eastern side of the site. Near the north, linear anomalies indicate the existence of a palaeaochannel and/or enclusure ditches.

Toward the west, the settlement shows a quasi-circular arrangement with a regular concentric organization, as if the set- tlement is divided by enclosures and/or ditches. The largest radius limiting the settlement is approximately $100 \mathrm{~m}$, whereas the concentric distribution of ditches presents an interval of $20 \mathrm{~m}-30 \mathrm{~m}$. The external boundaries show a large linear anomaly, probably a ditch, with different interruptions that perhaps correspond to entrances into the Neolithic tell. The inner part seems to have been divided by high magnetic structures, probably walls. The distinction between these archaeological features is clearest in the northern part of the settlement. The map also shows some radial partitioning, but the internal structuration still remains fuzzy. There is a high concentration of strong anomalies, mostly near linear anomalies on the top of the mound. Nevertheless, any anomaly related to a building is obvious. Toward the north, the largest features that we can see are two intense magnetic anomalies, which may be related to burnt buildings. The second related settlement cluster at the east is much smaller. It presents no clear internal subdivision, and the inner anomalies are hardly distinguishable.

Our interest in implementing an integrated approach on this site was to map more accurately the buildings on the summit to give an accurate idea of the whole settlement pattern and to analyse the nature of the linear features in the north. Another focus was to improve also the characterization of the circular delimitation. As we covered the main part of the tell with magnetics and electromagnetic (EM) techniques, we targeted additional areas on the summit and around the slopes with ground-penetrating radar (GPR). At a later point, the CMD was used to characterize geomorphological features around the site, such as

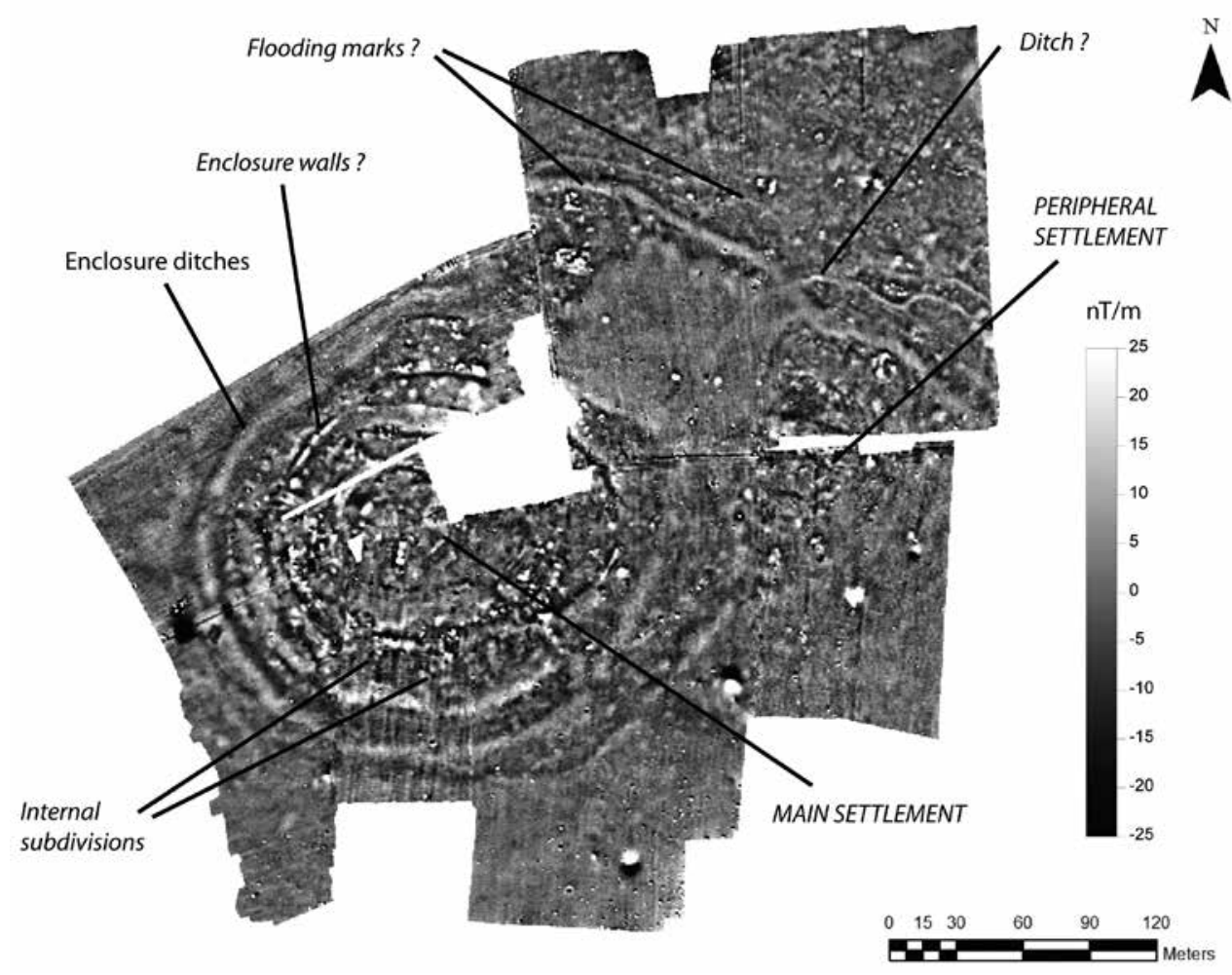

N FIGURE 2

Global view of the magnetic anomalies of the pseudo-gradient at Rizomilos 2. 


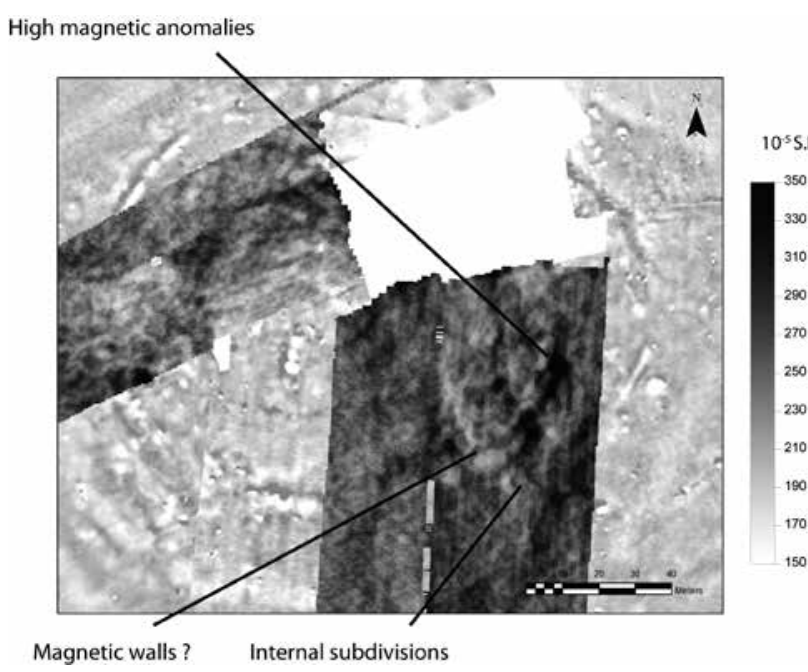

FIGURE 3

Map of the magnetic susceptibility (GEM2 - HCP) at Rizomilos 2 showing some information about the main structures of the site.

palaeaochannels and flooding deposits. In total, we mapped more than 10 ha of the settlement with magnetics, more than 3 ha with EM, and a limited area of 0.4 ha with GPR over the course of four working days.

The Noggin GPR did not provide clear results despite the $250-\mathrm{MHz}$ frequency of the antenna. The vertical electrical sounding used for the calibration of the EM instrument done with a Lipmann Gmbh, 4point Light $10 \mathrm{~W}$, shows a high conductive soil (three layers; thickness of the first layer $=0.5 \mathrm{~m}$, thickness of the second layer $=2.16 \mathrm{~m}$ with, respectively, $62.4 \Omega \cdot \mathrm{m}$, $25.1 \Omega \cdot \mathrm{m}$, and $43.8 \Omega \cdot \mathrm{m}$ ). These values are not higher than those from other sites where the GPR was efficient. As we also observed at Almiriotiki (see below), GPR was ineffective in detecting buildings on the top part of the magoula. This might be explained by the complexity of the different physical parameters of the site and by the sensor's low sensitivity to material such as mudbrick. This effect limits the effectiveness of an integrative approach based on the results of the GPR.

The GEM-2 was partially helpful in identifying magnetic targets, especially for high-value anomalies with strong linear features (Fig. 3). Overall, however, the results of the EM are redundant with magnetics. In this case, any large anomaly of magnetic susceptibility can explain the existence of linear anomalies in the magnetic data (as the concentric ditches), although both methods are sensitive to the induced magnetization.

Since magnetics detected probable palaeaochannels as linear anomalies in the northeastern part of the site, we further explored the area with the CMD-Mini explorer (Fig. 4). Although the conductivity presents some information, the data in general do not add anything substantial to the results from magnetics. The magnetic susceptibility and electrical conductivity surveys are similar, but the conductivity data do not even show the definition

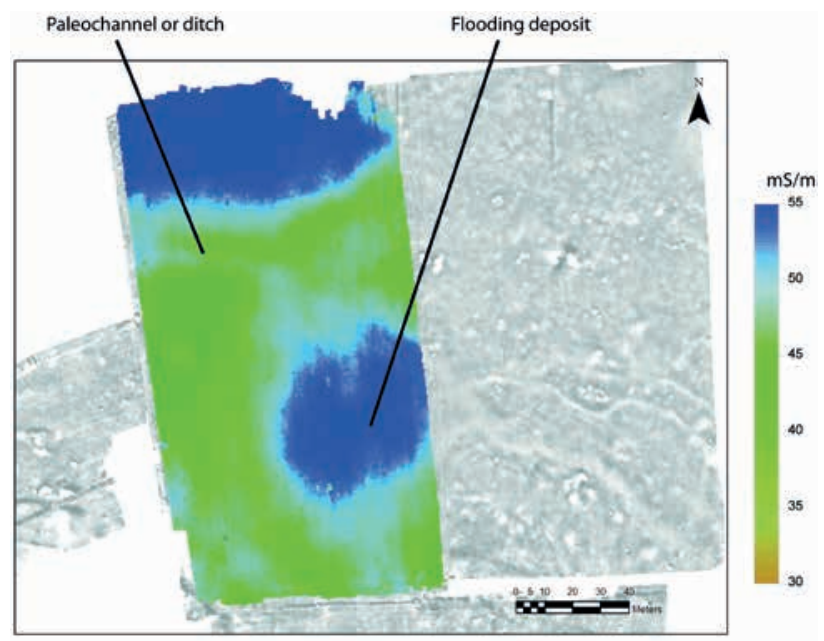

FIGURE 4

Map of the electrical conductivity (CMD miniexplorer - HCP) at Rizomilos 2 with some indication of the flooding deposits close to the main settlement.

of the palaeaochannels. The flooding deposit with a drainage network from low energy flooding could explain the variability of conductivity in this area. The presence of thin and welldefined linear anomalies is therefore probably not related to fluvial deposits; instead, they could be considered ditches. Considering the hydro-morphological aspect of this area and the existence of small and multiple ditches, we are tempted to see here a drainage network in this part of the settlement.

In our interpretation, we need to take into account that the quality of this dataset was probably not good enough to do an integrative analysis, but this does not mean that subsurface features are lacking. The limitations encountered in our survey are probably related to the construction material. In this instance, the cross interpretation of these datasets were not highly valuable to the same degree that they were at Almiriotiki.

\begin{abstract}
Almiriotiki
Almiriotiki proved to be an exceptional case study on the account of its large size and the abundance of near-surface architectural features. Most of the site stands within open agricultural fields where corn and wheat are cultivated. However, an olive grove near the top of the mound prevented us from mapping the entire site with the wide frame Sensys multi-sensor device. GPR and resistivity were partially employed to fill in the data gap. Overall, magnetics and EM covered an area of approximately 8 ha, whereas GPR was limited to just over 1 ha.

High-resolution multispectral satellite imagery from Almiriotiki shows only a small anomaly around the top of the magoula, although some palaeaochannels that surround the site are visible. Additional imagery on GoogleEarth shows linear features also at the southern part of the site, predicting a ditch system that we later discovered around the main settlement. However, only the magnetic survey shows architectural details of
\end{abstract}




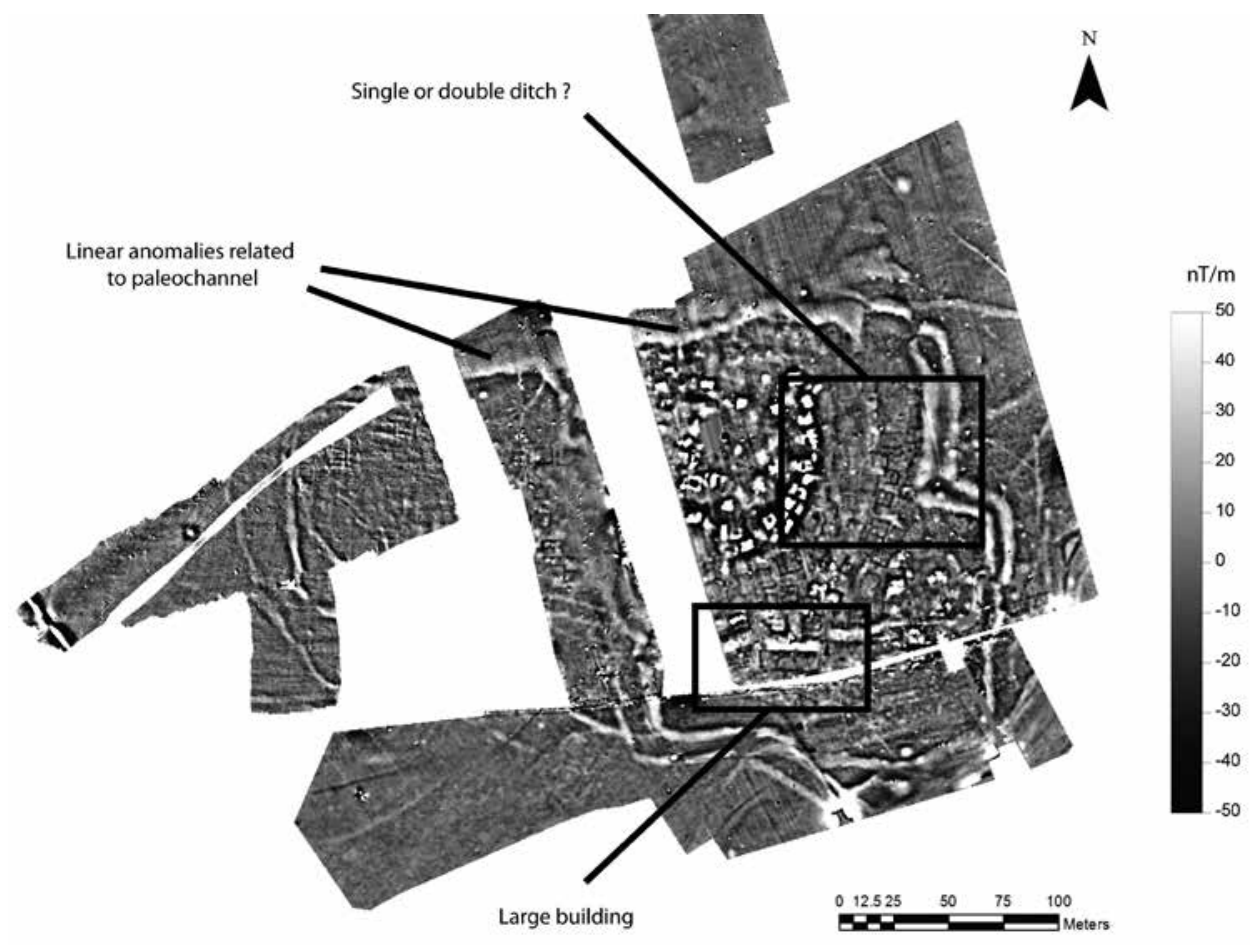

FIGURE 5

Global view of the magnetic anomalies of the pseudo-gradient at Almiriotiki showing the three areas deserving further attention: enclosure ditch, large building, and flooding deposits. the site in an astonishingly lucid manner and in an extensive way (Fig. 5).

The settlement is built atop a large mound with different projecting parts and extensions. The tell expands some distance to the west and east, but the northern side does not present a clear extension.

On the top of the magoula, we found at least 34 high magnetic anomalies of roughly rectilinear dimensions. This effect can come from the high intensity of the magnetic signals. It is difficult to say whether these archaeological features originate from magnetic building material such as basalt or from burnt clay as both of these have been noted as surface finds on this part of the site. Considering other Neolithic sites in the region, the second hypothesis that the buildings were constructed of burnt clay and mudbrick seems more likely. These intense anomalies are mainly distributed along a continuous line delimiting a space on the top part of the settlement with some scattered anomalies in the central part.

Around the central summit of Almiriotiki, we mapped more than 50 square or rectilinear anomalies that are distributed more or less in concentric patterns until they reach several large anomalies corresponding to an enclosure ditch. These extensions are clearest in the eastern and southern parts of the site, whereas the western side presents other types of anomalies. The appearance of small rectangular buildings (some with internal divisions) is consistently encountered all around the site, resulting from a probable constant depth of investigation, a similar preservation state, and a parallel type of construction. EM results show these architectural features as full anomalies resulting from the material filling the building (probably stone material as they are nonmagnetic). The magnetic survey only shows the linear anomalies corresponding to the walls since it is only able to detect the vertical contrasts of magnetization. One of these buildings looks completely different because of its larger dimensions. Around these buildings, several ditches enclose the mound. Unlike Dimini and Sesklo, surrounded by an enclosure wall, the magnetic linear anomalies correspond here to a ditch owing to the thickness of the anomaly and its magnetic orientation. At the eastern side, the magnetic survey revealed a double linear feature, whereas in another part, these ditches differentiate themselves by having different orientations. Finally, the ditches delimit different spaces of the settlement that are filled by different kinds of magnetic anomalies. We should also consider the presence of different ditches with different uses: the eastern side has massive ditches, whereas the western side reveals thin ditches crossing larger ones in the south. The different signatures probably relate to different systems, both of them related to the mound.

The high magnetic susceptibility of the soil provided an excellent contrast between the soil matrix and non-magnetic materials, such as stone building foundations. Likewise, the high magnetic material of some architectural features, such as burnt clay from mudbrick walls, was very distinct in the measurements. Human occupation probably increased the average value of magnetic susceptibility by handcraft activities as the erosion of high magnetic material around the top of the settlement enhances the contrast between the non-magnetic material and the surrounding soil matrix. 


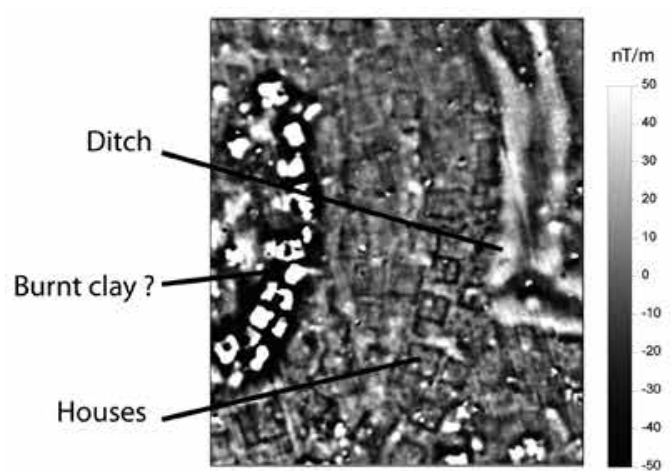

a.

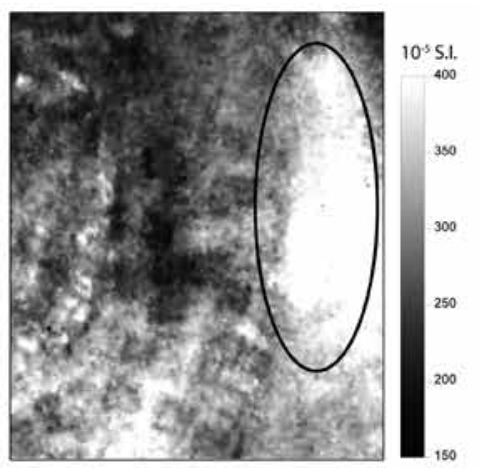

b.

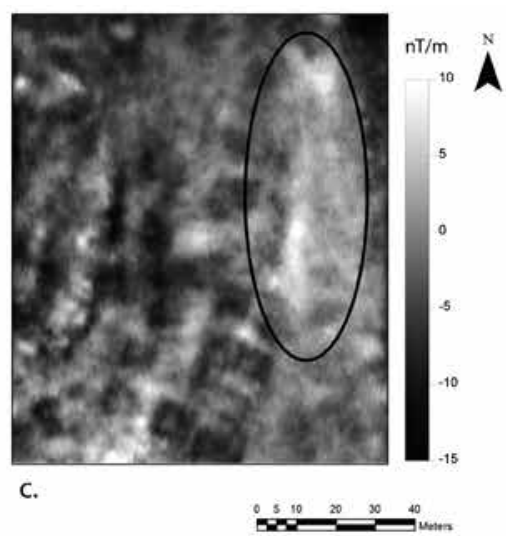

FIGURE 6

Comparison of the (a) magnetic data of the pseudo-gradient, (b) magnetic susceptibility for a depth of investigation of 1.7 meter (GEM2-HCP), and (c) the simulated magnetic survey based on the linear filtering of the previous magnetic susceptibility data. The three maps indicate the difference for the shape of the anomaly related to the ditch.
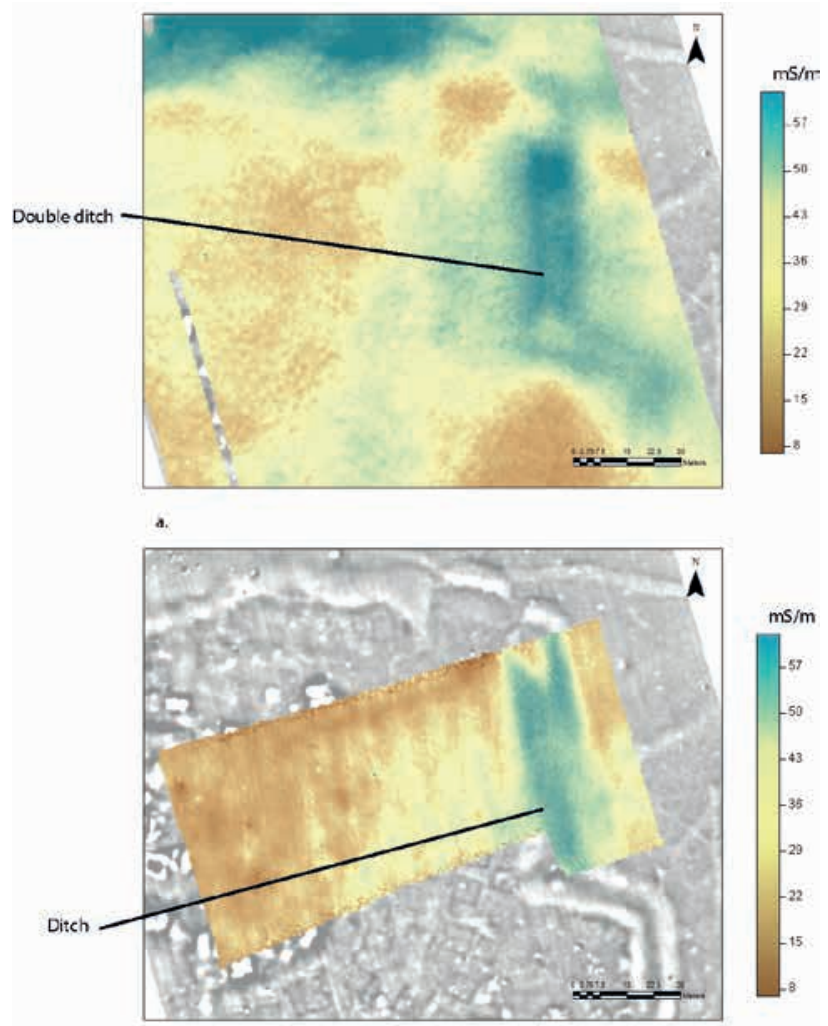

FIGURE $7^{\text {b. }}$

Difference of appearance of the double ditch at Almiriotiki with the (a) electrical conductivity for a depth of 2.5 meter (GEM2 - HCP) and for (b) the magnetic susceptibility for a depth of 1.3 meter (CMD miniexplorer - VCP).

The GPR was used in specific areas to target subsurface features already identified with magnetics and EM. It was successful in mapping the individual features of certain structures and clarifying details that were not distinct with the other methods, but in other areas, the results were not clear. To explain this difference, we verified whether the conductivity (around $30 \mathrm{mS} / \mathrm{m}$ and $40 \mathrm{mS} / \mathrm{m}$ ) was not too high to attenuate the GPR signal. Nevertheless, the electromagnetic measurements concern a depth of investigation of $2.5 \mathrm{~m}$, which is very deep considering the limitation of the GPR in conductive media, even for the 250-MHz antenna.

The initial target of the EM survey was to compliment the extensive coverage area of the magnetic survey and to gain a general idea of the usefulness of this methodology in detecting features. The second phase of the EM survey was implemented to target the geomorphology of the area, particularly in the identification of any palaeaochannels that may have affected the settlement. We were also interested in targeting the shape of the large eastern ditch with a multi-depth approach.

Our initial interpretation of the data at Almiriotiki led us to ponder new questions about specific targets. First, the monumental ditch (among other smaller ones) along the eastern side of the settlement appears to have enclosed the settlement. As the exact geometry and filling of this ditch was not immediately clear by a simple comparison of the magnetic data and the results from the GEM-2, we decided to check other methods. Second, the presence of a large building on the southern slopes of the magoula was particularly interesting, and we therefore chose to use the GPR in this area. Finally, some linear magnetic anomalies on the northern side of the hill appear to be cause by geomorphological features, but this attribution is still hypothetical considering the complexity of the magnetic signature for these kinds of features.

\section{Geometries and nature of the ditch enclosures}

Many of the ditches organized around the top of the site were mapped by magnetics. The magnetic data show a double magnetic and linear anomaly where the magnetic susceptibility from the GEM-2 only shows a single ditch and the electrical conductivity a division into two parts, but with a deep depth of investiga- 
tion. In the case of a thin and extended magnetic layer, the resulting anomalies will be two linear anomalies delimiting each border of the magnetic layer. The existence of two magnetic anomalies could be interpreted as the two borders of this layer, as long as the depth of this layer is not deep enough. The EM integrates a large volume of soil and could be at some point a kind of fuzzy recognition, for both electrical conductivity and magnetic susceptibility. A tightened double ditch would then appear as a single large linear anomaly.

The first solution to answering this question was to transform the signal of magnetic susceptibility as a simulated result of a magnetic survey (Fig. 6). For this, we considered a layer of magnetic susceptibility measured with the EM (Benech et al. 2002). Next, using linear filtering, we created the simulation of a fluxgate gradiometer similar to the one used during fieldwork. This simulation shows how a single ditch can create two quite distinct anomalies in the magnetic data. Even if the EM and magnetic data are not exactly similar, our approach shows the complexity of the magnetic measurements. Comparison between the simulated map and the experimental one shows a difference in intensity for the magnetic anomaly. This is the main limitation of this kind of simulation. The part of remnant magnetization is missed in the computation and the absolute value cannot be directly compared. In the case of a ditch, the resulting filing material probably has a low resultant remnant magnetization due to the random distribution of several magnetic grains (each has a specific and different magnetic orientation), thereby limiting this effect. Another explanation comes from the different depth of investigation of both methods. The EM takes into account only the top part of the soil until $1.5 \mathrm{~m}$, whereas the magnetic anomalies are the result of close and deep distributions of the total magnetization, resulting in stronger anomalies.

The second phase of measurement was more valuable due to the multiple depth of investigation in HCP geometries with the CMD-Mini explorer (Fig. 7). The three depths of investigation for the magnetic properties were still unclear regarding the separation of the ditch; nevertheless, the conductivity shows some differences starting at $2 \mathrm{~m}$. Given the different depth of investigation of the EM for the susceptibility and the conductivity, we can conclude that a single ditch on the top layer is separated into two parallel ditches on the lower part. This differentiation between the top and the lower part could come not only from the nature of the ditch but also from an episode of destruction, such as a flooding event. This approach is still empirical, but the use of

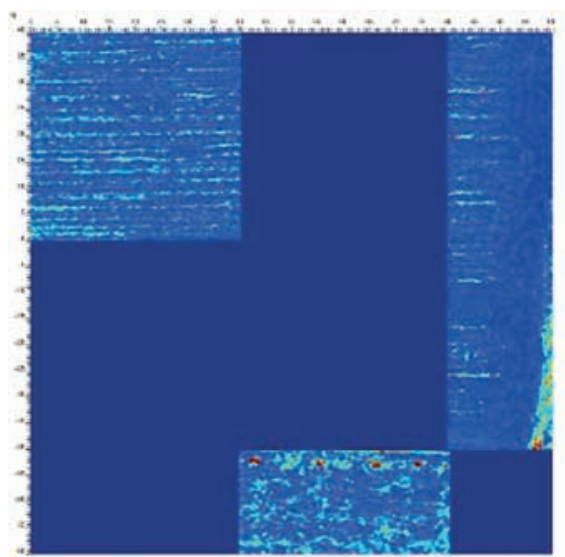

Slice depth: $40-50 \mathrm{~cm}$

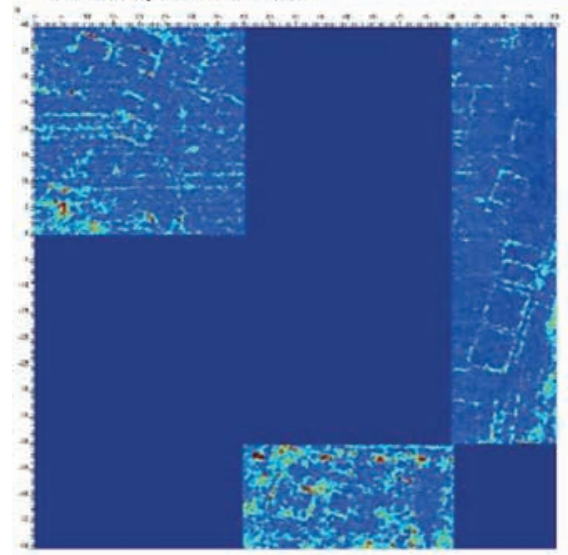

Slice depth: $110-120 \mathrm{~cm}$

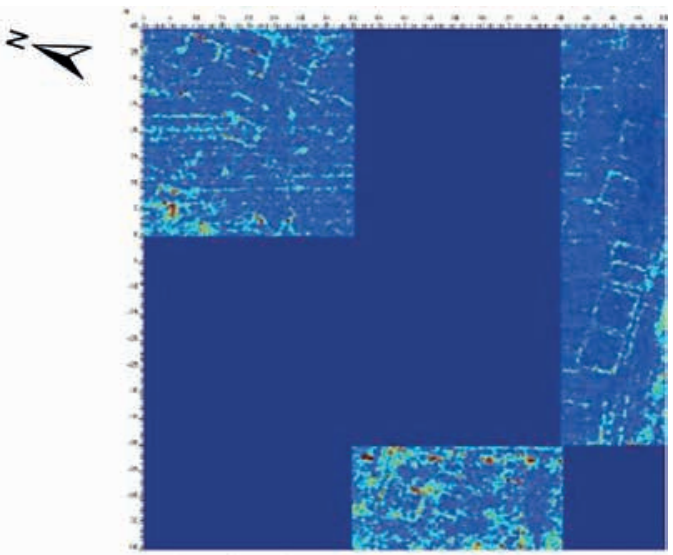

Slice depth: $70-80 \mathrm{~cm}$

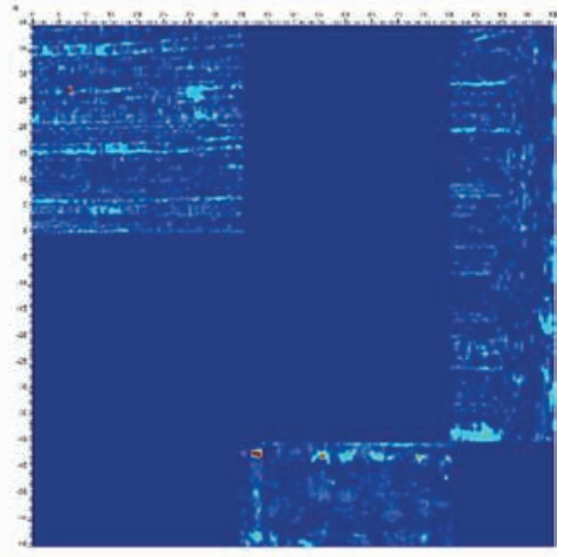

Slice depth: 120-130

\section{FIGURE 8}

Selected depth slices from the GPR survey at Almiriotiki magoula. 


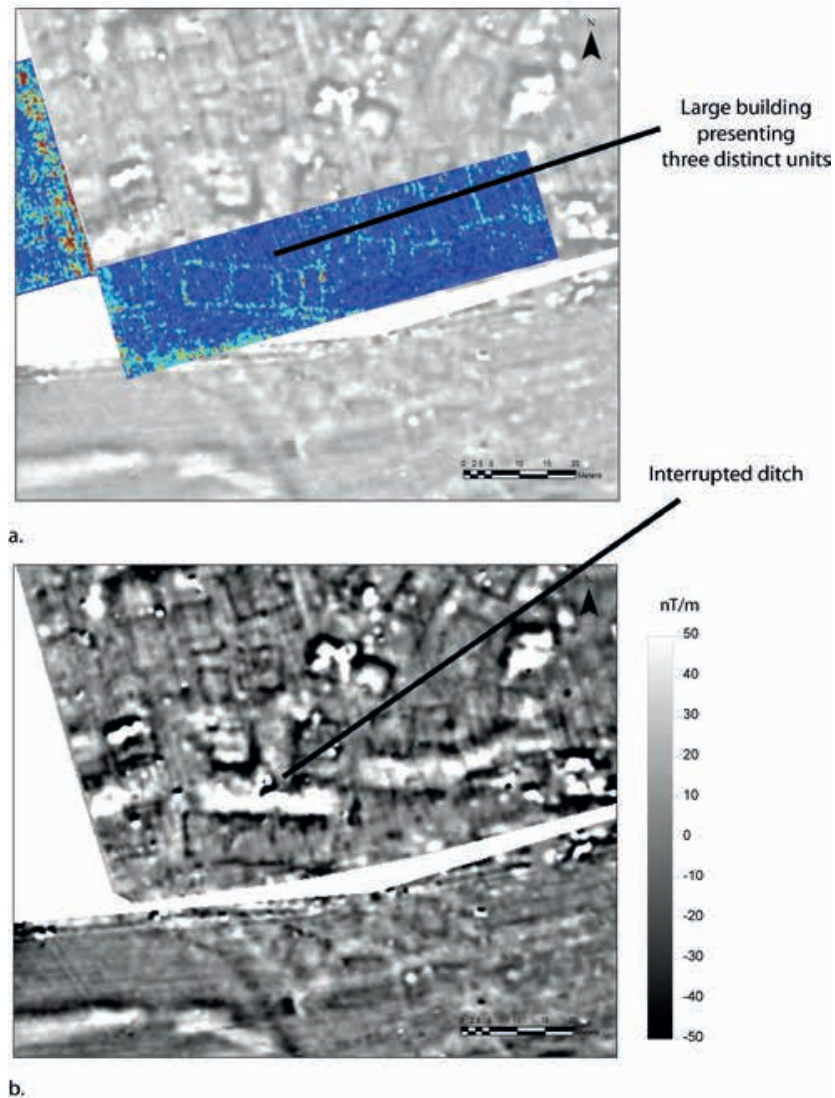

\section{FIGURE 9}

Comparison of the (a) GPR data (Noggin - $250 \mathrm{MHz}$ : Red, strong reflection, blue low reflection) at Almiriotiki with (b) the magnetic data of the pseudo-gradient showing differences in the definition of the large building and of the ditch. multiple depths of investigation is enough to reach such a conclusion. In this case, the integrative approach delivers some valuable information on the complexity of the target shape.

\section{Characterization of a large building}

One of the magnetic anomalies that was correlated to a building complex around the mound was very different from the others in terms of its size and its internal spatial distribution. To improve the mapping of this specific building, we rescanned this area with GPR to identify more clearly the walls of the building and its depth. The results proved to be highly valuable. The dense grid of measurement $(0.50 \mathrm{~m} \times 0.025 \mathrm{~m})$ reveals information about the exact configuration of the walls. The building was divided into three with dimensions of around $7.5 \mathrm{~m}$ in length for each room. The two western divisions appear to share a common wall, whereas the third one is separated by a narrow corridor from the others. Regarding the depth, the target appears at a depth of 0.70 $\mathrm{m}$ and remains clear until $1.2 \mathrm{~m}$ (Fig. 8). It is not certain whether the structure is deeper or if we have simply reached the limitation of the GPR's depth of penetration. This depth is also consistent regarding the magnetic and EM data and the depth of investigation of these two last methods. This detailed observation, which is extremely valuable from an archaeological point of view, was only possible through GPR after magnetics identified the location of the particular building (Fig. 9).

\section{Large conductivity recognition: New information on the impact of the flooding process}

Based on the magnetic data, some of the linear anomalies around the settlement are probably not from ditches but from the effects of geomorphological deposits. In order to test this hypothesis, we explored the conductivity of specific anomalies in order to find

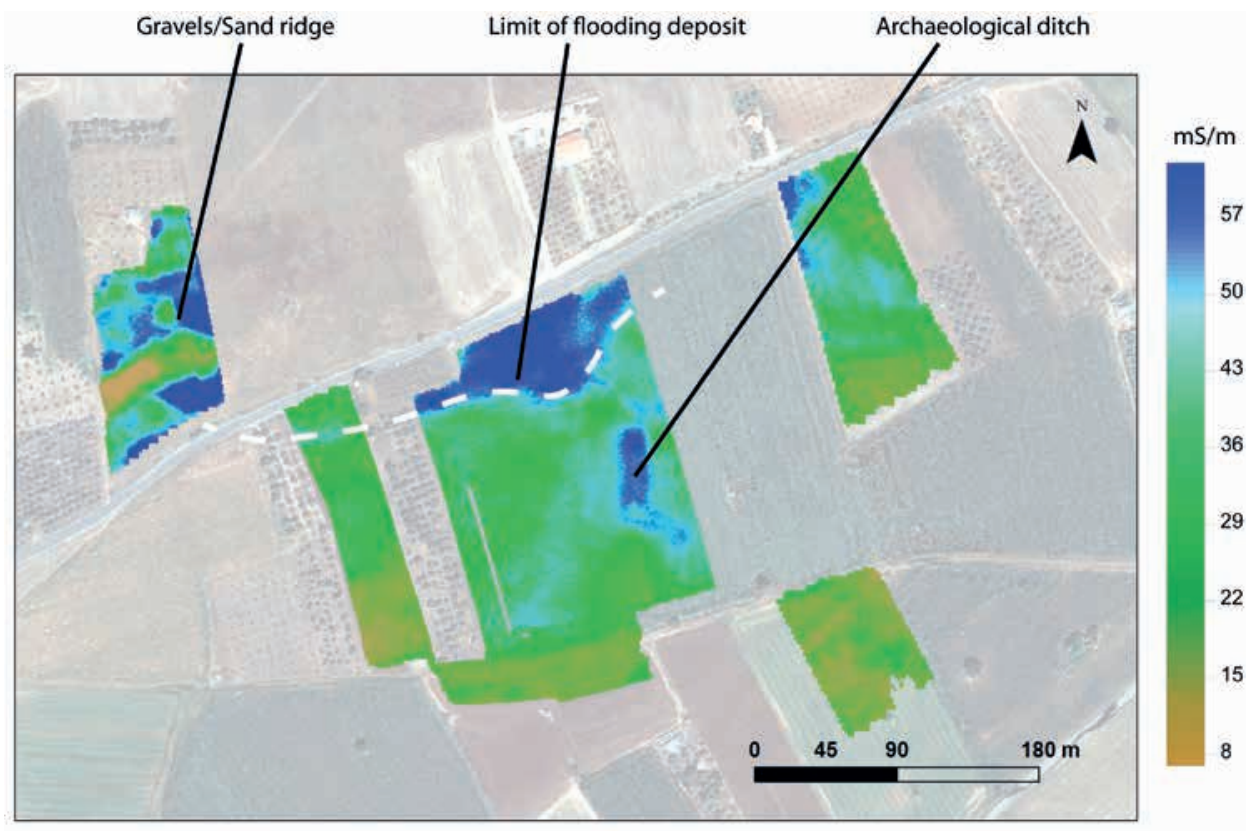

\section{FIGURE 10}

Map of the electrical conductivity (GEM2 - HCP) around Almiriotiki with some indication of a possible past flooding event and channel activities. 
evidence for palaeaochannels (Conyers et al. 2008; De Smedt et al. 2014). The magnetic susceptibility shows an increase in the magnetic susceptibility along the northern limits of the magoula, which is suddenly interrupted. This observation also fits with the electrical conductivity of the area because the magnetic anomalies are also located on the limits between conductive (flood deposit) and more resistive sediments (anthropogenic deposits). Three close areas were checked with a larger mesh size (a profile every $5 \mathrm{~m}$ ) in order to detect the main part of the palaeochannel around these limits (Fig. 10). At the northwestern area, we found a very clear linear anomaly that seems to correspond to a ridge of sand and gravel deposit from a palaeaochannel. This magnetic linear anomaly was interpreted as a signature of the limit of a thin magnetic layer and as a possible deposit of organic and iron content material. This analysis was useful in clarifying fluvial events around Almiriotiki, meaning that the archaeological interpretation needs to take into account the great variety of the origin of linear anomalies.

\section{CONCLUSION}

In this project, the main objective was to characterize the diversity of the settlements. This led us to adopt a large panel of tools to detect different features and different kinds of materials at various depths. We can discuss here the two main objectives of the project, i.e., characterization of the extension of the site and the accurate mapping of the buildings.

Magnetic data at Rizomilos 2 provide much information on the spatial organization of the site, such as the circular organization of the ditches and the walls on the top of the settlement. However, the other methods did not deliver any additional information of great substance. Yet at Almiriotiki, we have observed how GPR was useful for mapping the large building. At Rizomilos 2, the absence of strong reflection could also be caused by the absence of stone buildings. Only a general characterization of the site has been established by the different methods. No structures or strong anomalies corresponding to mudbrick buildings were identified. The best method here, as at Almiriotiki, seems to be magnetics on account of the high magnetic contrast of the soil in this area. Nonetheless, we still need to be cautious about this assumption because Almiriotiki demonstrates that magnetics can successfully identify both burnt and unburned structural remains.

For the first objective, our multi-method experiment was a resounding success in both cases. The integrative geophysical survey was a good way to map the extent of the site and to detect the complexity and the diversity of these prehistoric settlements, providing a new perspective of the spatial organization of Neolithic sites. The complexity of both magnetic and electromagnetic anomalies was clarified through the joint interpretation of both datasets. In addition, the extensive mapping of different properties was a good solution to overpass the simple objective of mapping archaeological features, providing valuable information related to the geomorphological nature of the landscape. Even if the magnetic survey is also a way to detect some of these natural anomalies, EM is often a better solution regarding the nature of the electrical conductivity and its close relation with the sediments diversity.

For the second goal, the accurate characterization of the features, the results are more diversified. Around the Neolithic mounds, the use of a variety of methods was helpful to enhance the characterization of some buildings. GPR was clearly useful in this context given its high spatial accuracy, the level of appearance, and depth of the archaeological targets. Elsewhere, EM data for the magnetic susceptibility was also revealing. By focusing on specific anomalies, it allowed us to understand and to characterize the depth of the magnetic signature and to show magnetic layers, particularly where the magnetic survey was inefficient.

Regarding the main part of the sites, i.e., the top part of the archaeological mounds, our integrated approach was more limited. The conductivity of the sediment and probably the use of adobe for building material, creates complexity in the site's stratigraphy. Several layers mask the accurate characterization of the buildings with GPR, particularly the deeper parts of a site. Considering the complexity of the stratigraphy and the thickness of the mounds, it is clear that the geophysical data only show the final upper phase of the settlement.

Overall, our two case studies demonstrate the advantages of using an integrated approach to map Neolithic sites. Buried archaeological features related to the latest occupation phases of these sites can be detected using geophysical techniques, and their spatial organization within the site and as part of the wider landscape can be better understood. For the extensive survey, the results show the variability of the patterns concerning the extension of the sites. In addition, the use of a multi-characterization approach minimizes uncertainty in the interpretation as it was the case for the characterization of the ditch or the main building complex at Almiriotiki. The next step is to improve the interpretation by using common processing as we started for the confrontation of the magnetic and EM data but also as joint inversion for multi-depth datasets. The use of recent techniques such as data fusion by a statistical approach could further enhance the interpretation and the results, particularly in noisy (disturbed strata) areas. This kind of additional work will help us better characterize a given context, overpassing the difficulties presented by complex archaeological sites, even if the quality of the dataset is first of all dependent of the material use to build the site and the geomorphological context, independently of the method used.

\section{ACKNOWLEDGEMENT}

This work was performed in the framework of the IGEAN ("Innovative Geophysical Approaches for the Study of Early Agricultural Villages of Neolithic Thessaly") Project, which is implemented under the "ARISTEIA" Action of the "OPERATIONAL PROGRAMME EDUCATION AND LIFELONG LEARNING" and is co-funded by the European Social Fund (ESF) and National Resources. 


\section{REFERENCES}

Agapiou A., Hadjimitsis D.G., Alexakis D. and Sarris A. 2012. Observatory validation of Neolithic tells ("Magoules") in the Thessalian plain, central Greece, using hyperspectral spectroradiometric data. Journal of Archaeological Science 39, 1499-1512.

Alexakis D., Sarris A., Astaras T. and Albanakis K. 2009. Detection of Neolithic settlements in Thessaly (Greece) through multispectral and hyperspectral satellite imagery. Sensors 9, 1167-1187.

Bailey D.W., Andreescu R., Howard A.J., Macklin M.G. and Mills S. 2002. Alluvial landscapes in the temperate Balkan Neolithic: transitions to tells. Antiquity 76, 349-355.

Bailey D.W., Tringham R., Bass J., Stevanović M., Hamilton M., Neumann H. et al. 1998. Expanding the dimensions of early agricultural tells: The Podgoritsa Archaeological Project, Bulgaria. Journal of Field Archaeology 25, 373-396.

Benech C., Tabbagh A. and Desvignes G. 2002. Joint inversion of EM and magnetic data for near-surface studies. Geophysics 67, 17291739.

Berge M.A. and Drahor M.G. 2011. Electrical resistivity tomography investigations of multilayered archaeological settlements: Part II - A case from Old Smyrna Höyük, Turkey. Archaeological Prospection 18, 291-302.

Cardarelli E. and Di Filippo G. 2009. Integrated geophysical methods for the characterisation of an archaeological site (Massenzio Basilica Roman forum, Rome, Italy). Journal of Applied Geophysics 68, 508521.

Casana J., Herrmann J.T. and Fogel A. 2008. Deep subsurface geophysical prospection at Tell Qarqur, Syria. Archaeological Prospection 15, 207-225.

Conyers L.B., Ernenwein E.G., Grealy M. and Lowe K.M. 2008. Electromagnetic conductivity mapping for site prediction in meandering river floodplains. Archaeological Prospection 15, 81-91.

Demoule J.-P. and Perlès C. 1993. The Greek Neolithic: a new review. Journal of World Prehistory 7, 355-416.

De Smedt P., Van Meirvenne M., Saey T., Baldwin E., Gaffney C. and Gaffney V. 2014. Unveiling the prehistoric landscape at Stonehenge through multi-receiver EMI. Journal of Archaeological Science 50, $16-23$.

Desvignes G., Tabbagh A. and Benech C. 1999. The determination of the depth of magnetic anomaly sources. Archaeological Prospection 6, 85-105.

Drahor M.G. 2006. Integrated geophysical studies in the upper part of Sardis archaeological site, Turkey. Journal of Applied Geophysics 59, 205-223.

Halstead P. 1992. Dimini and the "DMP": faunal remains and animal exploitation in Late Neolithic Thessaly. Annual of the British School at Athens 87, 29-59.

Hamilakis Y. and Kyparissi-Apostolika N. 2012. Koutroulou Magoula in central Greece: from the Neolithic to the present. Antiquity 86.

Keay S., Earl G., Hay S., Kay S., Ogden J. and Strutt K.D. 2009. The role of integrated geophysical survey methods in the assessment of archaeological landscapes: the case of Portus. Archaeological Prospection 16, 154-166.

Novo A., Vincent M.L. and Levy T.E. 2012. Geophysical surveys at Khirbat Faynan: an ancient mound site in Southern Jordan. International Journal of Geophysics 2012, 8.

Papadopoulos N.G., Sarris A., Parkinson W.A., Gyucha A., Yerkes R.W., Duffy P.R. et al. 2014. Electrical resistivity tomography for the modelling of cultural deposits and geomophological landscapes at Neolithic sites: a case study from Southeastern Hungary. Archaeological Prospection.
Papadopoulos N., Sarris A. and Salvi M.C. 2011. Reconstruction of the Archaeo-Landscape around the Area of the Magoula "Zerelia" in Almyros (Volos, NE Greece). $9^{\text {th }}$ International Conference of Archaeological Prospection, September 19-24, Izmir, Turkey.

Pétronille M., Thiesson J., Simon F.-X. and Buchsenschutz O. 2010. Magnetic signal prospecting using multiparameter measurements: the case study of the Gallic Site of Levroux. Archaeological Prospection 17, 141-150.

Sarris A, Adrimi-Sismani V., Topouzi S., Soetens S., Triantafyllidis F., Kevgas V. et al. 2001. Geophysical Prospection in Mycenaean Dimini, Magnesia (Greece). $4^{\text {th }}$ International Conference on Archaeological Prospection, Austrian Academy of Sciences, Vienna.

Sarris A. 2013. Multi+ or manifold geophysical prospection? In: Archaeology in the Digital Era - Volume II, e-Papers from the $40^{\text {th }}$ Conference on Computer Applications and Quantitative Methods in Archaeology (CAA2012), Southampton, 26-30 March 2012 (eds G. Earl, T. Sly, A. Chrysanthi, P. Murrieta-Flores, C. Papadopoulos, I. Romanowska and D. Wheatley). Amsterdam University Press.

Schmidt A. and Fazeli H. 2007. Tepe Ghabristan: a Chalcolithic tell buried in alluvium. Archaeological Prospection 14, 38-46.

Simon F.-X., Koziol A. and Thiesson J. 2012. Investigating magnetic ghosts on an early middle age settlement: comparison of data from stripped and non-stripped areas. Archaeological Prospection 19, 191-200.

Stevanović M. 1997. The age of clay: the social dynamics of house destruction. Journal of Anthropological Archaeology 16, 334-395.

Tabbagh A. 1984. On the comparison betzeen magnetic qnd electromagnetic prospection methods for magnetic features detection. Archaeometry 26, 171-182.

Tabbagh A. 1986. Applications and advantages of the Slingram electromagnetic method for archaeological prospecting. Geophysics 51, 576-584.

Thiesson J., Kessouri P., Schamper C. and Tabbagh A. 2014. Calibration of frequency-domain electromagnetic devices used in near-surface surveying. Near Surface Geophysics 12(4).

Toufexis G. 2006. I limni Karla (Voiviis) Kai I Anaskafi Ston Proistoriko Oikismo Sti Thesi Palioskala. Prota Symperasmata Kai Prooptikes [The Lake Karla (Viviis) and the Excavation at the Prehistoric Settlement at Palioskala. First Results and Perspectives]. In: Archaiologiko Ergo Thessalias Kai Stereas Elladas. Praktika Epistimonikis Synantisis 1, 55-64. Volos: Ministry of Education and University of Thessaly.

Tsokas G., Vargemezis G., Stambolidis A. and Kyparissi-Apostolika N. 2009. Geophysical Survey at Koutroulou Magoula, near Neo Monastiri (Prefecture of Phtiotida). In: Archaeologiko Ergo Thessalias kai Stereas Elladas Tomos II (ed A. Mazarakis-Ainian), pp. 829-837.

Vafidis A., Economou N., Ganiatsos Y., Manakou M., Poulioudis G., Sourlas G. et al. 2005. Integrated geophysical studies at ancient Itanos (Greece). Journal of Archaeological Science 32, 1023-1036.

Vouzaxakis K. 2008. Geographical patterns and theories of the intercommunal space in the Neolithic Thessaly. $\mathrm{PhD}$ thesis, Aristotle University of Thessaloniki, Greece.

Wijnen M.-H.J.M.N. 1981. The early Neolithic I settlement at Sesklo: an early farming community in Thessaly, Greece. Analecta Praehistorica Leidensia 14, 1-146.

Yerkes R.W., Sarris A., Frolking T., Parkinson W.A., Gyucha A., Hardy M. et al. 2007. Geophysical and geochemical investigations at two early copper age settlements in the Körös River Valley, Southeastern Hungary. Geoarchaeology 22, 845-871. 
